\title{
Investigation of personality characteristics of hearing impaired athletes participating in 2nd European youth hearing impaired athletics championships
}

\author{
Erdal DEMIR ${ }^{1}$, Kursad SERTBAS ${ }^{2}$, Ugur SENTURK ${ }^{3}$, Mustafa VURAL ${ }^{3}$ \\ ${ }^{1}$ Çanakkale Onsekiz Mart University. School of Physical Education and Sports, Çanakkale, Turkey \\ ${ }^{2}$ Sakarya University, School of Physical Education and Sports, Sakarya-Turkey \\ ${ }^{3}$ Sakarya University, Graduate School of Educational Sciences, Sakarya-Turkey \\ Address correspondence to E. Demir, erdaldemir23@hotmail.com.,
}

\begin{abstract}
The aim of this research is to assess the personality characteristics of national hearing impaired athletes and to evaluate the relationship between gender and branches with the personality characteristics. For this purpose, this research has been designed on screening model. The research was performed with Athletes Participating in 2nd European Youth Hearing Impaired Athletics Championships, held on 21-23 August 2014 in Trabzon. The research group consisted of 67 athletes including 26 from Turkey, 2 from Belgium, 3 from Estonia, 8 from Germany, 4 from Lithuania, 1 from the Netherlands, 12 from Poland, 9 from Russia and 2 from Spain. 34.3\% $(n=23)$ of athletes were female, 65.7\% $(n=44)$ consisted of male athletics. PERI (Personality Inventory) personality scale consisting of 25 items was used for measuring personality traits of national hearing impaired athletes in the research. PERI; is composed of 5 subgroups including openness to experience, sense of responsibility, extraversion, compatibleness and emotional stability. The scale was applied with face to face technical to athletes by two experts who know the language of the hearing impaired. In the analysis of the research data, frequency and percentage distribution, t-test, Kruskal-Wallis test and Mann-Whitney U tests were performed. In the result of the research; There were no significant differences between sport branches and gender and personality characteristics of the athletes. $(p>0.05)$. National hearing impaired athletes had in "not effective or low" level the personality trait of emotional stability and they defined as the individuals not feeling optimistic enough, easy-tempered and having a high level of anxiety. But they had in "effective or high" level the personality traits of sense of responsibility and they defined as disciplined individuals who do not give up in the face of difficulties themselves, pay attention to details, are planned in everything they do.
\end{abstract}

Keywords: Athletics, hearing impaired athletes, personality.

\section{INTRODUCTION}

Personality is defined as consistent patterns of behavior and personality internal processes resulting from the individual himself (1). Larsen \& Buss defined the personality as a set of psychological characteristics. This set constitutes psychological mechanics, internal world, permanent adaptations, gender interaction, and adaptation, psychological thoughts of the individual and the physical and social environment of the individual (8).

Although the concept of personality has attracted through the centuries as a leg of the social life of man, its scientific development started when the personality psychology emerged as a separate scientific discipline from other social sciences in the 1930s. (10).
The personality is defined as the entirety of organized, spiritual, physical and functional properties which makes the person different from others and which is observable in social relations (10).

According to spiritualists, the personality is defined as the totality of characteristic and distinctive behaviors of the individual. The word of personality often passes in daily conversations. While talking about the one, most of the time phrases such as " having a reliable person", " weak personality" "impersonal" are used and definitions are made (11).

The sport is the matching of motoric skills within certain rules. Motor skills are possible to classify as biomechanical or kinetic, physiological and psychomotor. Performance and win- 
conditioned athlete faces with a great deal of stress before the contest because, the competition is not only a physical strain but also spiritual and social stress. Distress created by the competition concerns is one of the factors that affect negatively the performance of athletes. Sports psychology activates in dealing with these factors. Competition stress may lead to degradations on demonstrating the skills of both athletes and coaches in a safe way (10).

Various studies have been made in order to determine the relationship between sport and personality. Is there a feature that distinguishes elite athletes from non-elite athletes, defensive players from offensive player, those sporting from those not making? Personality characteristics are continuous and constant features. In sports, the studies carried out on personality have emerged since the last 40 years and according to the results obtained, the athletes have showed significant differences when compared to non-athletes. Athletes are more confident, extroverted, competitive, independent, objective, intelligent and less anxious (6). Davidson and Moran-Miller stated that the character education occurs with morality and citizenship development and the generic developments occur through physical education and sport (4).

\section{MATERIAL \& METHOD}

Due to the identification and description of the present situation in the study, it was carried out on screening model. Screening model is the research approach aiming to describe an existing condition in past or present (7).

Personality traits of deaf athletes in the study are evaluated in terms of the relationship between gender, branch and country variables; therefore it has been made to determine the relationship and thus designed according to the relational screening model from the screening models. Data collection tool used in the study has been applied by face to face technique to the participant. The scales have been applied by two officials knowing the hearing impaired speech language to provide communication with hearing impaired athletes. This scale has been administered in the morning and evening hours or training hours. It has been provided that the athletes can answer data scale in a friendly way without having to rush. There is no selection criteria in the determination of the participants and based on a voluntary. 2nd European Youth Hearing Impaired Athletics Championships which the research has been carried out was held in Trabzon on 21-23 August 2014. 119 national hearing impaired athletes from 15 countries participated in Championship. These countries; Turkey, Belgium, Belarus, Bulgaria, Croatia, Czech Republic, Estonia, Hungary, Germany, Latvia, Lithuania, Netherlands, Poland, Russia and Spain. The research group consisted of $n=67$ national hearing impaired athletes.

Personality scale has been used as a data collection tool in the research. Information concerning participants' gender, age, country, athletics branch took part in the scale. In order to measure the participants' personality traits, PERI personality scale short form has been used, which was developed by (9). This scale has been developed according to the five factor personality theory and measures the five main personality traits (openness to experience, sense of responsibility, extraversion, compatibleness and emotional stability.) Scale contains a total of 25 regulated expressions in 5 Likert scale. (5: absolutely agree, 1: absolutely not agree). There are the five each statements for each personality dimension in the scale. Statements contained in scale; for me, this statement has been answered by the choices (a) absolutely correct, (b) correct, (c) neither correct nor, (d) not correct, (e) absolutely not correct. Cronbach's alpha values calculated for sizes in scale vary between .70 to .88 . Turkish version has been used for Turkish national hearing impaired athletes, English version for foreign athletes.

The resulting data has been transferred to computer, taking the average score has been achieved by (9). T-test, Kruskal-Wallis test and Mann-Whitney $U$ tests have been used in order to determine the differentiation status of the scale scores. The level of significance has been taken as 0.05 .

\section{RESULTS}

Personality traits of the responsibility has the highest average score with 4:04 in the mean scores of the personality traits of hearing impaired national athletes. It has the relevant behaviors in "effective or high" level with this average. It has been determined that Personality trait of emotional stability has the lowest average scores (2.87)" and not effective or low" level. Extraversion, openness to experience and compatibleness personality traits have "partially effective or situational". 
Table 2. T-test made for relationship between gender and personality characteristics of national hearing impaired athletes.

\begin{tabular}{|c|c|c|c|c|c|c|}
\hline Personality Characteristics & Sex & $\mathrm{n}$ & mean & $\mathrm{Sd}$ & $t$ & $\mathrm{p}$ \\
\hline \multirow[t]{2}{*}{ Openness to experience } & Female & 23 & 3.91 & .525 & 1.083 & .283 \\
\hline & Male & 44 & 3.73 & .683 & & \\
\hline \multirow[t]{2}{*}{ Extraversion } & Female & 23 & 3.83 & .581 & .188 & .852 \\
\hline & Male & 44 & 3.80 & .644 & & \\
\hline \multirow[t]{2}{*}{ Emotional Stability } & Female & 23 & 3.17 & 1.062 & 1.956 & .055 \\
\hline & Male & 44 & 2.71 & .837 & & \\
\hline \multirow[t]{2}{*}{ Compatibleness } & Female & 23 & 4.00 & .803 & .726 & .470 \\
\hline & Male & 44 & 3.87 & .645 & & \\
\hline \multirow[t]{2}{*}{ Sense of responsibility } & Female & 23 & 4.25 & .680 & 1.799 & .077 \\
\hline & Male & 44 & 3.93 & .698 & & \\
\hline
\end{tabular}

Table 3. Kruskall Wallis test made for relationship between branches and personality characteristics of national hearing impaired athletes.

\begin{tabular}{|c|c|c|c|c|c|c|}
\hline Personality Characteristics & Sports Branch & $\mathrm{n}$ & Mean Rank & $\mathrm{X}^{2}$ & $\mathrm{df}$ & $\mathrm{p}$ \\
\hline \multirow[t]{4}{*}{ Openness to experience } & Short Distance & 34 & 34.37 & 1.279 & 3 & .734 \\
\hline & Middle Distance & 17 & 30.09 & & & \\
\hline & Throws & 8 & 38.75 & & & \\
\hline & Leaps & 8 & 36.00 & & & \\
\hline \multirow[t]{4}{*}{ Extraversion } & Short Distance & 34 & 29.41 & 5.876 & 3 & .118 \\
\hline & Middle Distance & 17 & 41.32 & & & \\
\hline & Throws & 8 & 30.44 & & & \\
\hline & Leaps & 8 & 41.50 & & & \\
\hline \multirow[t]{4}{*}{ Emotional Stability } & Short Distance & 34 & 36.56 & 1.917 & 3 & .590 \\
\hline & Middle Distance & 17 & 28.62 & & & \\
\hline & Throws & 8 & 34.25 & & & \\
\hline & Leaps & 8 & 34.31 & & & \\
\hline \multirow[t]{4}{*}{ Compatibleness } & Short Distance & 34 & 34.47 & 2.217 & 3 & .529 \\
\hline & Middle Distance & 17 & 30.41 & & & \\
\hline & Throws & 8 & 30.75 & & & \\
\hline & Leaps & 8 & 30.12 & & & \\
\hline \multirow[t]{4}{*}{ Sense of responsibility } & Short Distance & 34 & 34.93 & .210 & 3 & .976 \\
\hline & Middle Distance & 17 & 32.76 & & & \\
\hline & Throws & 8 & 34.38 & & & \\
\hline & Leaps & 8 & 32.31 & & & \\
\hline
\end{tabular}

${ }^{*} \mathrm{P}>0.05$

There were no significant differences between personality traits and gender of the study group ( $\mathrm{p}>$ 0.05). However, it was determined that the mean score of female athletes is higher than men in all subscales.

There were no significant differences between the branches and personality characteristics of national hearing impaired athletes $(p>0.05)$.

\section{DISCUSSION}

The distribution by gender of athletes; consisted of $34.3 \%(n=23)$ female, $65.7 \%(n=44)$ male athletics. It was determined that $28.4 \%$ of the study group $(\mathrm{n}=19)$ were 16 years old, $31.3 \%(\mathrm{n}=$ $21), 17$ years old, $17.9 \%(\mathrm{n}=12) 18$ years old and 22.4 $\%(n=15), 19$ years old. The mean age of the study group was found as $17.34(\mathrm{Sd}=1.122) .26$ athletes from Turkey, 2 from Belgium, 3 from Estonia, 8 from Germany, 4 from Lithuania, 1 from the Netherlands, 12 from Poland, 9 from Russia and 2 from Spain participated in the research. It was determined that $50.72 \mathrm{~s} \%$ of athletes $(\mathrm{n}=34)$ had short distance and $25.4 \%(\mathrm{n}=17)$ middle distance runner, $11.9 \%(\mathrm{n}=8)$ throws and the remaining $11.9 \%(\mathrm{n}=8)$ leaps braches.

When studied the national mean scores of he personality traits of hearing impaired athletes (Table 1 ); it was determined that they received the highest mean score in personality traits of sense of responsibility and had " effective or high" level. Thus, the relevant behaviors exhibited in most cases. 
Athletics identified as disciplined individuals who do not give up in the face of difficulties themselves, pay attention to details, are planned in everything they do (5).

Evaluated vocational personality qualifications of physical education teachers and concluded that they have high sense of responsibilities. As a result of research of Mean scores of sense of responsibility of swimmers were found to be medium-level. Personality characteristics of the physical education teachers were evaluated by a "high" score in the research performed (2).

It was determined that National hearing impaired athletes had in "not effective or low" level with the lowest average scores on emotional stability personality trait. Thus it was concluded that athletes did not have this personality and they often exhibited the opposite or negative examples of the related behaviors. They defined as persons not feeling optimistic enough themselves, easytempered and having high anxiety levels. The similar results were obtained in the study of stated that the swimmers had "medium" level on the emotional stability personality traits. Concluded that emotional stability personality traits of professional basketball players had "high" average $(2,5)$.

It was determined that national hearing impaired athletes had "partially effective or situational" on personality traits of openness to experience and exhibited the relevant behaviors in certain situations. Thus they defined as the individuals trying to produce new ideas, to have different interests, to be creative and not to be single-minded. Found "medium" level the average score of personality traits on openness to experience of swimmers $(2,5)$.

Determined that physical education teachers had the personality traits on openness to experience in " situational or partially effective" level. National hearing impaired athletes had the personality traits of extraversion in " partially effective or situational" level. With this score, they partially have personality trait and exhibit the relevant behaviors in certain situations. Athletics were defined as the individuals being enough social, not having a doubt themselves, not having difficulty in protecting their interests and indicating proximity enough to others. Personality traits of extraversion were found as " medium" in swimmers (2). Situational or partially effective" in physical education teachers $(3,5)$. Found as "adequate" the personality traits of extraversion of physical education teachers' trainees.

National hearing impaired athletes had the personality traits of compatibleness in " partially effective or situational" level. With this score, they partially have personality trait and exhibit the relevant behaviors in certain situations. Thus, they defined as the individuals trying to think enough to others, to be helpful and to be compatible with other (2). Concluded that swimmers had in "medium" level, but physical education teacher had in "high or effective" level.

There were no significant differences between the gender and personality traits of national hearing impaired athletes (Table 2). There were also no significant differences between personality traits with short distance, medium distance, throw and leap branches of athletes (Table 3).

National hearing impaired athletes had in "not effective or low" level the personality trait of emotional stability and they defined as the individuals not feeling optimistic enough, easytempered and having a high level of anxiety. But they had in "effective or high" level the personality traits of sense of responsibility and they defined as disciplined individuals who do not give up in the face of difficulties themselves, pay attention to details, are planned in everything they do.

\section{REFERENCES}

1. Burger JM. Personality. Transleted by Erguvan-Sarıoglu, I.D. Kaknus Publishing. İstanbul, 2006.

2. Cavallera GM, Passerini A, Pepe A. Personality traits and the role of gender in swimmers at the leisure level. Social Behavior and Personality, 2013; 41(4): 693-704.

3. Çolakoğlu T. Defining personality types of students in schools of physical education and sports. International Journal of Academic Research. 2013; 5(2): 302-307.

4. Davidson ML, Moran-Miller KE. Character development in sport. Journal of Research in Character Education, 2005; 3(2): 121.

5. Demir E. Evaluation of the perception of vocational personality qualification of physical education teachers who are working in secondary schools. Doctoral Thesis. Istanbul: Marmara University. 2012.

6. Karageorghis C, Terry PC. Inside Sport Psychology. Human Kinetics, 2011.

7. Karasar N. Scientific Research Method. Nobel Publishing. Ankara, 2003.

8. Larsen RJ, Buss DM. Personality psychology: domains of knowledge about human nature. McGraw-Hill Book Company. Boston, 2008. 
9. Sevinc L, Peri (Personality Inventory) Technic Handbook. Assesment Systems. Istanbul, 2005.

10. Soysal A. çalişma yaşaminda kişilik tipleri: bir literatür taramasi. Çimento İşveren Dergisi, 2008: 2.
11. Ulusoy Y, Gönener A, Taşkıran Y, Sertbaş K, Kolayiş H, Investigate personality properties of Turkish junior and $\mathrm{A}$ women handball players. International Sports Sciences Congress, Abstract book, Antalya, 2002. 